\title{
Corporate skin: Biosocial relations, tropes, and institutions in prosthetics research and development
}

\begin{tabular}{|c|l|}
\hline Journal: & Journal Of Material Culture \\
\hline Manuscript ID & MCU-17-0015.R1 \\
\hline Keywords: & $\begin{array}{l}\text { Apprenticeship, Biosociality, Corporation, Organic trope, Prosthesis, R\&D, } \\
\text { skin }\end{array}$ \\
\hline Abstract: & $\begin{array}{l}\text { Modern orthopaedic prosthetics imitate biological organs or their } \\
\text { functions, interacting with the body of amputees, and are designed and } \\
\text { manufactured corporately. Thus, prosthetics constitute a privileged } \\
\text { vantage point to witness the intermingling of society and nature, how } \\
\text { biosocial relations and institutions are understood, negotiated and } \\
\text { constituted. We develop methodologies of apprenticeship with a } \\
\text { worldwide corporate leader in the development and manufacture of non- } \\
\text { invasive orthopaedics, to explore the biosocial relations, the tropes, and } \\
\text { the institutions involved in the research and development of lower limb } \\
\text { prosthetics. The ethnography reveals how understandings of biosocial } \\
\text { relations are influenced by and simultaneously permeate corporate } \\
\text { institutional practices, constituting specific organic tropes, such as the } \\
\text { corporate skin. This trope reflects the continuous negotiation of } \\
\text { understandings of what the skin is and what it does, of the biosocial } \\
\text { relations associated with it, of the history of the company, its products, } \\
\text { and how its institutional practices are being shaped by these } \\
\text { understandings. }\end{array}$ \\
\hline
\end{tabular}




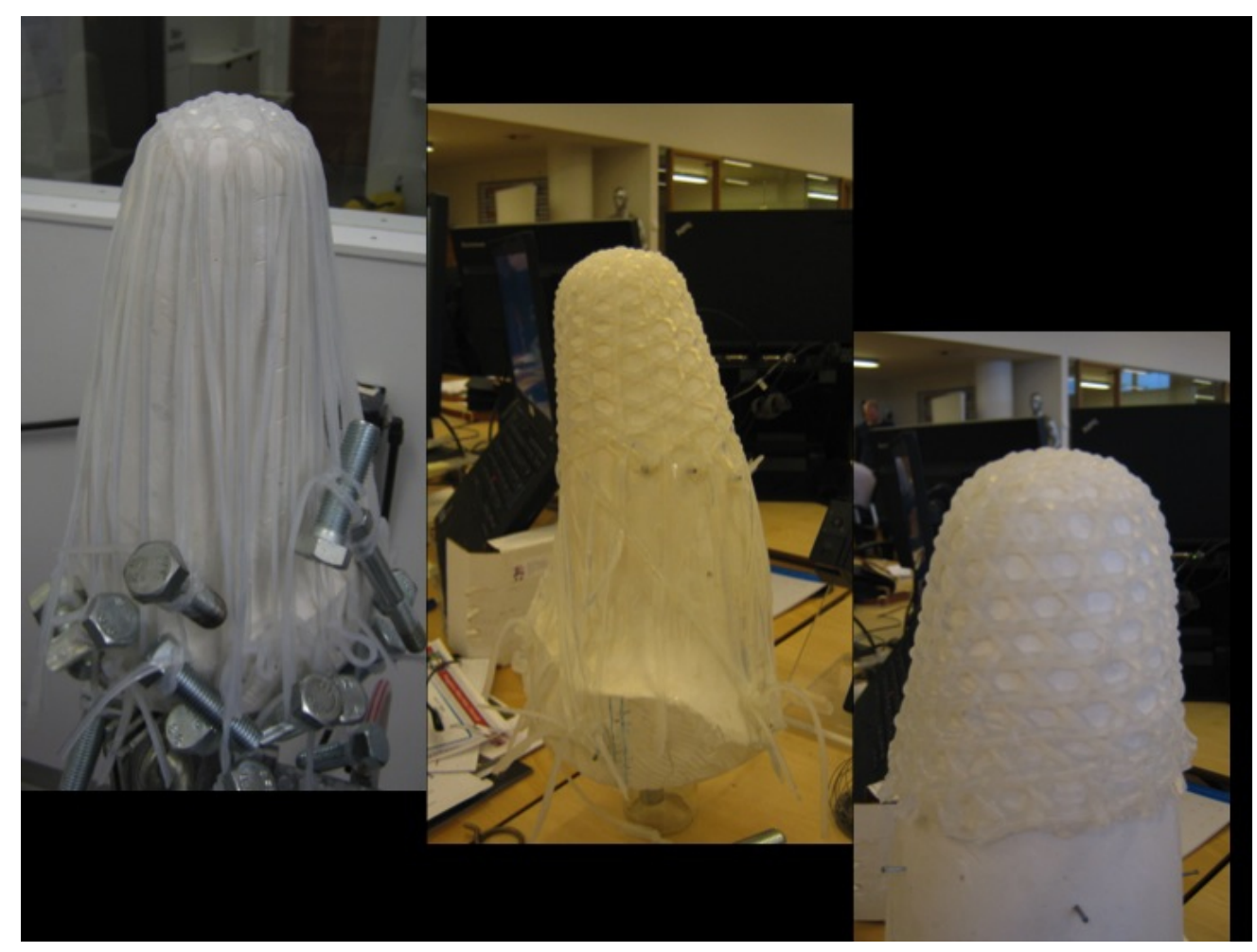

Prototypes of breathing liner

$254 \times 190 \mathrm{~mm}(72 \times 72$ DPI $)$ 
Íslendingar í húð og hár

Popular Icelandic saying

Lit. Icelandic in skin and hair

Trans. Icelandic to the backbone

\section{Introduction}

This article explores the creative dynamics through which lower-limb prosthetic devices are developed at Össur, a world-leading multinational biomedical corporation based in Iceland. It is the result of the collaborative analysis by the authors (X and Z) of an ethnography developed by Z, employing methodologies of apprenticeship at the corporation's Division of Research and Development (R\&D). Through the analysis of the ethnography we enquire after the biosocial relations (Palsson, 2009), the tropes, and institutions that arise along the corporate production of prosthetic body parts. The ethnography suggests an organic trope: the corporate skin, which establishes specific relations between some of the prosthesis' components produced by the corporation, the understanding of the organs they emulate, and specific institutional dynamics of the corporation relating to its approach to R\&D. We suggest that by being involved and dealing with specific biosocial relations, the employees of the corporation develop explicit and tacit understandings about biosocial relations. These understandings constitute tropes, cognitive devices that may permeate onto the way employees relate to one another, substantiating or destabilizing corporate institutions. Thereby, we explore how the processes that create and 
modify prostheses are influenced by, and simultaneously constitute a corporate body. In this way, we revisit how institutions are substantiated, as well as potentialities and possibilities offered by organic tropes to understand both specific societies and bodies.

Biological material is increasingly the subject of engineering, banking, reproduction, and exchange, stretching our understanding of the body, of tools, property, identity, agency, and knowledge, conflating rhetorical figures and concepts. The description and broad implications of the intrusion of life itself into economics and politics represent some of the most challenging issues on the academic agenda at the beginning of the twenty-first century. This is highlighted by a series of recent studies in the social sciences, humanities, and life sciences, often associated with "biosociality" (Rabinow, 1999; Ingold and Palsson, 2013; Lock and Nguyen, 2010) and the "culturing" of life (Landecker, 2009).

At the outset, Rabinow (1999) proposed biosociality to counter sociobiological claims asserting that human behaviours had underlying biological mechanisms shared with other organisms. Biosociality, he suggested would focus on how human society is embedded but furthermore how it involves, affects, and transforms biological organisms and their mechanisms. This definition and an emphasis on the social phenomena elicited by the human genome project led to a restricted understanding of biosociality, as a form of (human) sociality mediated by specific biological phenomena which could be altered in the process, but which by themselves did not need to be considered as social. The 'bio' in that case simply circumscribes the realm through which sociality is enacted (Dimond et al., 2015). 
Nonetheless, deeper scrutiny into of the history of biology and the biology of history reveal that this social transformation of living organisms, this culturing of life is not a recent process, circumscribed to the turn of the $21^{\text {st }}$ century. In the nineteenth century, physiology elaborated its models of metabolism departing from the technological development of combustion engines. These physiological models grounded agricultural and livestock practices (Landecker, 2016), altering the ways organisms related to one another and to humans (Steve et al., 2013). They were also the basis for many of the developments of political economy that defined ideological trends dominating the twentieth century.

Through this process living beings have been far from passive substrates of human sociality. Landecker (2016) shows how early in the twentieth century antibiotic production industrialized bacterial metabolism but also how, through antimicrobial resistance, microbes challenged biological knowledge diluting the assumed distinction between history and evolution. It has become increasingly evident that social relations are neither limited to humans, nor simply mediated and enabled by a pre-determined biological substratum. Rather living beings and our relations with or through them have complex properties which may warrant a strong interpretation of the adjective biosocial (Ingold and Palsson, 2013). Hence, it is necessary to revise and to explore those biosocial relations (Palsson, 2009), and to question an understanding of institutions built upon the idea of the contraposition of a human social realm defined by intentionality and a biological non-human realm fixed, pre-determined, and hence paradoxically, both passive and deterministic. This turn of events requires revisiting old tropes relating body and society. 
Mary Douglas argues that institutions are conventions funded on analogy, which:

“...grounds the institution at once in nature and in reason by discovering that the institution's formal structures correspond to formal structures in non-human realms" (Douglas, 1986: 55)

Cognitive conventions justify conventions grounding their legitimacy on an alleged fit with the nature of the universe, they also facilitate the communication and extrapolation of conventions across multiple realms of social interaction, reducing the cognitive load and social attrition of those participating of the institution. However, we will argue that analogy is only one of many different tropes, of many alternative cognitive devices, some of which do not require us to presuppose the separation between human and non-human realms. Tropes are rhetorical figures, ways of displacing meaning and structuring a discourse. Tropes are ways of setting ideas in motion, ways of establishing relations between things, thereby influencing our grip on reality. Although, generally referring to speech, especially persuasive speech, tropes play a fundamental role in the construction of knowledge, in the development of technology, and therefore in the modification and constitution of some biosocial relations. The specific tropes people use reflect the relations they perceive amongst things in the world, but also the relations they may establish with them (Ricoeur, 1980 [1975]). Although classifications of tropes are highly variable, there are arguably four master tropes: metaphor, metonym, synecdoche and irony (Burke, 1969: 503-517). Metaphor poses analogical relations between the properties of unrelated things, shading alternative perspectives on each other, 
metonym derives relations of contiguity or association reducing related things with distinct properties to one another, synecdoche identifies holographic or representational relations, and irony highlights the ulterior differences arising from taking sameness to its final consequences. These tropes overlap to a certain degree, a single sentence may use simultaneously two or more of these tropes or even be interpreted as demonstrating different tropes.

At least since Plato (Shorey, 1969), through Radcliffe-Brown (1940), and Mauss (1934), and still today in some neuroscientific discourses (Llinás, 2001) parts of the body and tools are likened to one another, and in turn stand for the persons employing them: the head of state, the military arms, the manual labour... metonymically likening the bodies, technologies, and society, the organic trope has often reduced the body and its organs to some of their potential functions, simultaneously explaining society as a coherent and functional entity, bound to work in a specific way for a given purpose. In so doing, the organic trope has often essentialized and justified given hierarchies, and modes of control over those constituting society (Scheper-Hughes and Lock, 1987; Martin, 2010; Douglas, 2002: 78).

Prosthetics is one of the fields through which the organic trope has been questioned. The failure, loss or congenital lack of any of the body's organs can challenge or reaffirm working understandings of the body (Sharp, 2013; Cohen, 2012). Prosthetics and transplants have a highly disruptive potential, the capacity of altering the subsisting organism and our understanding of it, raising in the process endless moral conundrums (Sharp, 2013). Prostheses imitate and emphasize certain qualities, deemed fundamental, necessary or desirable, and while aiming to re-establish a given sameness they generate the very disabilities 
they set out to resolve (Jain, 1999). Thus, prosthetics question normality itself, the grounds for differentiation, the underlying hierarchies, and the institutions grounded on them. Prostheses have been used metonymically to illustrate our relations with technology in general(e.g. Haraway, 1985), and synecdochally to describe the relations of some citizens to their particular societies (e.g. Cresswell, 2009; French, 1994; Nelson, 2001; Wright, 2001).

Nonetheless, Kurzman (2001) and Sobchack (2006) note that when treated as metaphors (or perhaps rather as metonyms) the organic and prosthetic tropes, all too frequently simplify all the terms involved. Sobchack criticises the tropology of the prosthetic. She argues that treating all technology as prosthetic, is vague and reductionist in its illustration of structures, functions, and institutional practices. Meanwhile, she argues that the usage of the prosthetic as a trope for the role of the individual in the society often has an objectifying tendency. It privileges essentialist understandings of the body that fail to recognize how amputees perceive their prosthesis as something distinct but also as something continuous, functionally belonging to the same body (Sobchack, 2006). However, this is precisely what the synecdoche trope would imply. Thus, although these criticisms must be taken into account they do not represent a reason to drop the tropes altogether, but rather, a call to explore their potential complexity more deeply. Not only as cognitive devices to illustrate the relations people, but as means to understand how people are understanding and acting on the world.

As Miloslavljevic points out, through the process of rehabilitation bodies are 'literally re-membered' (2013: 53). Rehabilitation requires amputees to incorporate the prosthetic limb and learn to walk again, but also to re-people 
their world, to re-construct social relations, and gain access to institutions afforded by their limbs. We will argue that a similar re-membering is at work through the research and development of prosthetics. These are processes through which novel insights, innovations and frequently intern collaborators are incorporated into the corporation and its products. The challenges faced through these processes evidence how much we take for granted of the workings of those organs and how little we understand about them, revealing previously neglected biosocial relations. Prosthetics' R\&D involves the instantiation and interaction between multiple people, from diverse backgrounds working with a variety of tropes, specific understandings of the body in its physical but also in its political sense. Thus we will argue that prostheses and prostheses design are negotiated interpretations of the organs they seek to replace or enhance. We will contend further that institutional structures and dynamics may not only correspond but relate to the specific and complex biosocial relations instantiated through prostheses. Furthermore, we will argue that the understandings of the body and of technology that underly and arise through those productive processes permeate on how members of the corporation interact with one another, in the organization of the corporation and its architecture.

There is not a single organic trope, but rather specific tropes that arise out of the conjunction between the dynamics of specific institutions and the biosocial relations in which they are involved. Thus, addressing the corporate creative and productive processes from which prostheses originate may enlighten our understanding of the physical and social bodies.

Össur is a multinational corporation producing state of the art prosthetics mainly for high-end (wealthy or well insured) amputees. The corporation is 
widely known as the producer of the Cheetah legs, the elastic blades made of carbon layered fibres, resembling the feline hind-paws, which caused uproar and raised paradoxical questions about the 'unfair' advantages of a Paralympian athletes (e.g. Oskar Pistorius) competing in able-bodied Olympics. Össur, is also renown for producing bionic feet, knees and legs, with propriosensors, artificial intelligence systems and actuators (Össur Corporate, 2014b) ${ }^{1}$.

Through this text we will explore some of the issues faced by the company as it attempts to modify the characteristics of one of its most basic but also most important products: the liner, which could be described as a prosthetic callous skin. We explore the practices and experiences involved in the process of design, the interactions amongst biomedical engineers and designers, as well as their interactions with amputees, technologies, and the corporation through the collaborative analysis (by authors X and Z) of an ethnography (developed by Z), which employed methodologies of apprenticeship through a two-month internship with the Liner Unit of the division of $R \& D$ of Össur.

In methodologies of apprenticeship the researcher follows a training process with a community of practice, and aims to become proficient in the skilled practices of the research subjects (Coy, 1989; Gieser, 2008; Marchand, 2010; Simpson, 2006). These methodologies situate the researchers providing them with a role within the community, a perspective that is true both to their developing capacities and to the changing expectations of the group. For this reason, they afford a particular sensibility to understanding practices and ontologies of a community of practice. In apprenticeship methodologies the functions of the ways of doing are experienced, situated, contextualized and emotionally tensed with meaning. 
Through the internship period researcher $\mathrm{Z}$ worked five days a week from 8:00 to 16:00, with a team of 8 researchers, and two amputee prototype testers. He also interacted with the members of four other research teams, and with staff from other divisions, including various interns. Field notes were recorded on the field site and elaborated afterwards. This experience suggested insights into how biosocial relations and hierarchies, within a biomedical corporation, simultaneously are constituted and affect the creative processes that shape prostheses, enskill interns, and sensitize them to the biosocial relations lived by amputees, as well as those of their own bodies.

Through the analysis, we examine how diverse actors (researchers, amputees, materials, technologies, prostheses, corporations et cetera) contribute to the constitution of bodies: mediating, being affected, caring for, instrumentalizing or translating one another. First, we examine the image the corporation projects of itself to its employees, customers and investors, and through which it perpetuates its existence. Then we examine the 'organic growth' of its structures and developments. Finally, we explore the interactions surrounding the creative processes of research and development in prosthetics.

\section{Corporate life: The growth of a corporate body}

Located on the industrial research parks in the eastern outskirts of Reykjavik, the headquarters of Össur are a couple of massive buildings interconnected by a glass-bridge. We (Authors X and Z) arrived early for a meeting with the director of Research and Development, so we take the chance to explore the architecture. The entrance has a somewhat hermetic look, no reception, only stairs leading up and a display with a few artefacts: the liner, the socket and the knee-brace on one 
side; the polycarbonate feet and the artificial knee on the other. We head for the building where the meeting is actually going to take place, a huge depot with a massive showcase window displaying a banner with the motto 'life without limitations' over a biomechanical analysis facility. People are busily designing, coding, or writing. At the entrance there is another display showing a wide range of ankle, knee, and hip bracing support systems. Askur, ${ }^{2}$ the director of R\&D, arrives and leads us to one of the meeting rooms.

Askur remarks that one of the things that motivates his willingness to take an anthropologist on board is finding out what drives his researchers, and exploring ways to stimulate them. What inspires people to be in Össur? 'Clearly, it is not money, they could be getting twice their salary elsewhere...' He replies to himself, '... a part of it is the challenge, then there is the clinical side, and also the smile on the patients' face.' His interests seem partly derived from his role as research director. He is looking for ways to stimulate his employees. At the same time, he is doing public relations, advertising the company and its humane, faceto-face, approach. Then he elaborates on his general interest in the social implications of technology.

Askur offers three possible scenarios for research. First, he mentions the Silicone Liner Platform, the backbone of the company, constituted by a small group of researchers. Then there is the research on neuronal interfaces. In the middle there is another group developing research on artificial knees, but this is much more complex research. We settle for the Silicone Liner Platform, which after all is the basis of the company. Össur is now recognized for bionic (mechatronic) achievements, which are echoed in the cyborgian lemma 'life 
without limitations', however the membrane delimiting, or the interphase differentiating, is its more fundamental trope.

In our naïve thoughts about lower-limb-prostheses, be they wooden or bionic legs, the supporting structure and the artificial intelligence respectively appear more relevant, and hardly any thought is given to the fact that the skin of the residual limb requires protection from the sharp edges of the residual bone or to how prostheses are attached. But in strict order of the issues prostheses must to resolve, the functions they must perform, first stands the protection and cushioning of the residual limb, second the attachment mechanism, third the projected structure, fourth the articulating mechanism(s), and lastly active control devices.

The company was built, and is still largely reliant, on the Iceross liner (the Icelandic roll-on silicone socket) - an interface which fulfils the role of a callous skin, protecting the residual limb and preserving its shape, affording suspension, cushioning and an adhesive interface linking it to the prosthesis (Kristinsson, 1993).

The development of the Iceross liner is embedded strongly and starkly associated with the frosty perspectives and economic politics of Cold War Iceland. It benefitted from and articulated personal, technical, political and cultural circumstances. Össur's liner. First, the personal motivations and capabilities of Össur Kristinsson, an amputee himself due to a congenital malformation, met with the background of the Cold War. The politics of the Cold War exerted different pressures in the North Atlantic than elsewhere. The strategic importance of Iceland in relation to the Soviet Union called for large investments of resources from the US and Western European countries 
promoting Icelandic Industrialization. This context fostered Kristinsson's training as a prosthestist, his access to silicone rubber (Polydimethylsiloxane), and financial support for his enterprises.

Moreover, the Circumpolar environment and Icelandic ways of dwelling in it afford certain understandings of the skin, its workings and its importance. As is suggested by the popular Icelandic saying in the epigraph above " - in skin and hair", the skin connotes fundamental aspects of identity. Like for other Circumpolar inhabitants (Sonne, 2007), for Icelanders fundamental identity envelops rather than structures from within. Icelandic circumpolar dwelling practices related to insulation from the cold (socks, caps, et cetera) and from the water (oilskins) and perhaps latex condoms, which became popular after Second World War, provided multiple tropes, a set of solutions to resolve the issues of support and mechanic insulation.

In a tropical environment the tropes of the sock or the cap would not have been available. Moreover, prototypes of the silicon liner would likely have been quickly dismissed; as even the latest versions of the finished product are difficult to bear.

It is not only the liner, other aspects of the corporation reflect Iceland, its history and environment. As Mímir puts it on his first advice, as I (researcher Z) am approaching his R\&D team:

At heart we [Icelandic engineers and designers] are still fishermen, we have a hands-on approach to problem solving and do not like hierarchies, we speak our mind, and that does not mean that we are being rude, just honest... you will know when we are being rude. So, speak your mind. Try to be useful and get involved. 
Spatial organization reflects Mímir's observation regarding hierarchies. In general terms Össur displays a highly horizontal organization, which is more in line with Nordic practice than with American, British, French or German models. The product managers, the platform leaders, the director and the VPE (Vice President Executive) share workspace side-by-side workers and interns in groups of 3 pairs of conjoined desks, which somewhat recall six oared fishing boats. The Liner group meets on a long table, on an open room next to the desks. Although such a table could lead to a cephalization of the group, the heading places normally remain chair-less. After a quick introduction, I meet the core team of eight staff members. The following day, I will meet a more extended group of fifteen staff members that includes liaisons with other divisions.

After the meeting Garðar, one of the researchers, volunteers to introduce me to Össur through a tour through the premises on our way to the canteen. Garðar's intention is to start from the beginning with an 'amputee,' so we walk at high-speed through the building looking for one.

Besides the biomechanical analysis facilities, the ground floor houses the R\&D offices. I enquire about this subdivision of the research laboratories. Garðar replies that formerly all $R \& D$ if not all the company used to be located in one office. Garðar comments:

Össur started as a small business, precisely developing liners, trying to do life more comfortable for amputees. It grew organically, joining other small businesses with similar aims, similar reasons for being in business. As it grew it occupied the whole building and later this showcase building, which used to be an automobile store. 
In this narrative, 'organic growth' is explained as the development of cooperating alliances amongst peer businesses with a common goal. The result of this developing cooperation is also, what is colloquially understood as an 'organic growth', i.e. An euphemism for growing in a disordered and opportunistic fashion to occupy available spaces. Later conversations, with researchers from some the conjoined businesses revealed the aggressively predatorial aspects of the mergers.

This ambiguity, slurring between cooperation and predation, is also latent in timelines and various displays of prosthetics that portray the history of the corporation, bearing remembrance to a museum of natural history: From the humble beginnings of the early liner, to the shiny "symbionic leg" through a series of iterations, mergers, and developments. Although, the different companies seem to stand in a relation of parity through the display, the corporate narrative ultimately describes how the company based on a prosthetic callous skin - a membrane mediating the interactions between the amputee and the prostheses -swallowed companies specialized in prosthetic functions, often more visible and deemed of higher hierarchical importance.

As the corporation developed further the architectural distribution had to be harmonized, Garðar adds:

The organization into different research platforms is a recent development. Downstairs, it aims to articulate R\&D testing and the prosthetist orthotist clinic. So that designers and engineers become aware of the problems arising on the ground with amputees running right through their desks. The problem of the setting is that it makes 
testing very public, which is not always so convenient given the traumas associated with amputation.

The arrangement has an additional result: it turns R\&D into a highly visible form of participant advertisement. It is a risky bet; users can be enticed or repelled by the spotlight of R\&D involvement. This way of conducting business attests to a drastic difference with other biomedical engineering contexts. While engineers developing heart prosthetics (Sharp, 2013) rarely interact directly with patients, the development of limb prosthetics involves close contact and continuous interactions with amputees. Through the tour, Garðar continuously tests my reaction to the word amputee. He asks everyone aloud if they have seen an amputee: 'have you seen an amputee, I need an amputee'. Then he adds:

Everyone in Össur has a direct and personal relation with amputees, many designers and engineers are amputees, or have a daughter or a son who are an amputee. I know it sounds a bit like Disney, but it is truth.

He is partially referring to Össur Kristinsson, Finn Gramnas, Van Phillips and Hugh Herr, some of the 'Innovators', a group of foundational figures of the company (Össur Corporate, 2014a) ${ }^{3}$ who either were amputees or closely related to amputees, and thereby, became highly motivated researchers. Highliting the role of these figures the company seeks to foster its rapport between with amputees.

The role of the amputee-engineer, becomes obscured as I talk with Teodoro, VPE of R\&D. He points out that Össur has traditionally been an engineering company that adapted engineering solutions towards the 
development of prosthetics. In his opinion, this has led towards over-engineered prosthetics. Like the apps in mobiles and other high-tech devices, the features of Össur prosthetics exceed usage capabilities of users while at the same time failing to fulfil their needs. Now Össur is veering towards a greater emphasis on the medical needs of the patient. Now, the prosthetic leg has to be considered as a part of the patient, which has to be considered as a whole.

Össur employs a considerable number of amputees, many of them are part of Team Össur, others, have been test subjects, and become qualified as engineers and designers for the company. Normally, they are not considered as patients or costumers, two categories which are applied depending on the setting. Finally, we come across Símon, it is not evident but he is wearing an above the knee prosthesis. Garðar comments on the paradox, they are aware of the discrepancy between their test subjects and their expected users. The latter are old, frequently sedentary, with tendency to overweight and low life expectancies, while the former are young and athletic. Nonetheless, he adds, 'you have to have some ethics and cannot go about testing stuff on an old fragile grandma.'

\section{Dialogues of research and development, scavenging for ideas}

A few days after my induction, I am following people around, trying to make myself useful, which as I will come to understand means developing an independent project, addressing any of the multiple issues the team must resolve. The task I will end up engaging on is designing a liner for the tropics, a liner that breaths or rather that transpires, avoiding the discomforts caused by accumulated sweat to its circumpolar predecessor under hot climates. 
Wandering through the corporation, I find Friðrik and Líf clearing lab storage space. Bag after bag of prototypes in which they effort and ingenuity had been invested, but which has to be, tidied up, re-accommodated in blue boxes, and sent to the storage room.

While cleaning up, they are also fishing for re-usable materials and ideas. A couple of items draw their attention. An old lady knitted them on silicon for Friðrik. The idea was to produce a breathing liner. Apparently, the same airtightness, which allows the clutch lock to work, remains one of the main problems of silicone liners. It does not allow the stump to breath, so the stump, which bears higher blood pressure and thereby temperature, sweats creating great discomfort. The problem is not easy to resolve. To start with, if you make holes into the silicone it is torn apart. So, the idea was that if you knitted silicon it would naturally have holes and breathe. However, Friðrik points out:

$$
\begin{aligned}
& \text { The problem at the design stage is that knitting is time consuming } \\
& \text { and requires a lot of skill. However, once you have the design it is } \\
& \text { easy to program a machine to do it, then you can play and combine } \\
& \text { materials, the possibilities are endless. }
\end{aligned}
$$

Some days later, Friðrik welcomes me with an evil smirk, he has a project in mind for me: developing the knitted liner. Somewhat reluctantly, I end up accepting. Mímir cheers the news. A couple of weeks later, on a general meeting with the R\&D VPE it will become evident that resolving the airtight sweaty issues of the Iceross liner is a major project of the Liner Platform. It is a project of crucial strategic importance, given that Össur attempts to grow into the tropical 'Emerging markets,' where sweatiness is a greater concern. 
I start by thinking that the liner has some resemblance to the cod-end of a trawling net. So, I dive into it. Such a net with fixed knots could work. However, I am told there were two unresolved issues in previous attempts: first, how to close the structure without using sutures at the distal end, and second that superimposed threads result in painful pressure points. So, neither the cod-end nor the fixed knots would be very helpful. After some thought, I consider the potentiality of flat reed baskets like the ones used as a cushioning surface in tropical furniture. Their hexagonal pattern would lend stable support and allow breathing.

\section{Reinventing the basket}

The project of the woven liner, a solution to the sweaty issues of the airtight circumpolar Iceross, was suggested to me as a laborious task. Nevertheless, its aims coincide with my background: Coming from a tropical context, I am aware of similar problems and of technologies which might resolve them, such as certain basketry techniques. There are various issues to resolve, although I am aware of the uses of basketry, I ignore the manufacturing techniques, I lack the materials, my experience with warmer climates contravenes the original idea and desires of my peer-mentor, and his experience with amputees indicates that my solution will be problematic for the skin of their residual limb. The project allows me to explore how researchers interact with materials, with other researchers and with amputees and with their residual limbs.

Through Youtube, I get access to some videos showing how to weave on the hexagonal pattern (Nabila, 2013) ${ }^{4}$. Making a flat surface out of the hexagonal pattern is not too difficult. However, weaving a pronouncedly concave structure, 
like a liner, presents more subtleties. Ultimately, these are geometrical questions but initially my problems are derived from the properties of the elastic bands, which unlike flat reed or bamboo are too flaccid. After devising a scaffold method, I bang my head repeatedly trying to figure out how to make the pronounced curvature. The solution unfolds by itself when I stop making calculations and simply keep adding strips as if there was no issue to be resolved. It will take me much longer to decipher what I did, and how I have done it. Still, after understanding it, I had to rely on a sort of automatism to repeat it.

After celebrating this initial success, Jónas enquires about how I see myself in relation to the company and the ways I might contribute to its aims. Although contributing to the process of appropriation of traditional knowledge by a multinational corporation is somewhat troubling, perhaps there is no better acknowledgement. Moreover, personally the experience of the design process has been very rewarding. There is a slight silence. As the conversation proceeds, Jónas points out that:

$$
\begin{aligned}
& \text { Designing a product is like giving birth. It takes time. You cannot } \\
& \text { rush the process, hiring nine mothers to deliver the baby in one } \\
& \text { month. }
\end{aligned}
$$

Later in the afternoon, Askur who is passing by my desk comments that the basket is starting to look like something interesting. Friðrik comments that it looks 'pretty', but then he questions my choice of materials, the thickness of the strips and the size of the holes.

The thing is that the feet have a layer of tightly packed cushioning fat. The end of the stump lacks that layer, and there is nothing to 
protect the skin from the bone, which swims loose without attachment. The liner has to provide cushioning and maintain the shape of the stump. On the other hand, the holes are too big so the skin is going to be pulled through the holes producing circulation problems and pain.

Friðrik wants me to make the strips thicker and the holes smaller. I try to explain to him that the size of the holes is proportional to the width and thickness of the strips. But somehow, I cannot get the message across, drawings and equations are no use. He only wants to see prototypes. I try to explain that there should be a minimal size of the holes, allowing the structure to breathe. He replies there are breathing fabrics, which have microscopic pores. I believe this is the right woven pattern. It could and should be thinner, so that the holes were smaller, but that would also require more time spent weaving, which would slow down the production of prototypes. So, instead I work on my materials and start enquiring about ways of doing silicone strips.

Mímir indicates the easiest way to make strips would be to make a silicone sheet of the desired thickness and cut strips of the desired length and width. He suggests some initial dimensions, a compromise between the size of the holes and strip thickness, and tells me to ask Sólbjörg for instructions on working with silicone; she is the expert in that field.

At first Sólbjörg seems reluctant. She seems to evaluate whether the task of helping me out is another load on her back or recognition of her competencies. It is both. She helps me get sorted out with the silicone mixer, and moreover suggests an additive, producing a silky texture and matted effect, which should make weaving easier. The downside is that additives will increase the curing 
time of silicone. Matted silicone will take a day to cure instead of five minutes, so I am left on hold with my working space busy until the following day. Impatient, I start doing some experiments sticking different kinds of textile strips at the edges of the sheet, until I see some silicone rubber sticking out of a bin of the laboratory.

I weave the basic pattern and test the feeling of the overlapping silicone strips. The squared strips cut from a sheet will be problematic. The corners of the strips are elevated at the points of overlap, constituting sharp cutting edges, which hurt even with small pressure. I remember this is not a problem for traditional baskets because flat reed is semi-cylindrical so that one side of the network presents rounded contours.

I imitate the flat reed shape cutting a tube in half and using it as a mould for my strips, the results are optimal, the point of superposition is smooth and even cushioned but the process is cumbersome and difficult to replicate. So, I start asking around for ways to make a rounded strip mould.

The flow of ideas while you are working with your hands is strange. The work in progress and the materials frequently suggest many possibilities. Some are mistakes or problems which when regarded carefully and performed systematically could become solutions. The problem is that these ideas usually seem to appear while you are performing another task.

Over lunch, I mention to other interns my observations from basket making. They reply that most designers or engineers will have a similar experience. While working with their prototypes, they learn by doing. To a certain degree they incorporate the new stuff they are learning onto the prototype, the crucial point however is testing. Testing a prototype means 
testing an implementation of an idea. Examining whether it works as imagined. A prototype could be tested in multiple ways, a prototype liner can be submitted to tension, pressure or heat. A material may be examined for its texture or appearance. The ultimate test for a prototype is to have amputees put it on and describe their experience, in a controlled setting, but that requires approvals from ethical committees and is expensive. Testing a prototype, they come to see whether they are on the right track or whether they have to drop certain features for the following prototypes or develop independent prototypes to test those features.

Later, I discuss with Friðrik the progress of the basket. He points out that I do not have to test everything in the same prototype; 'in fact,' he indicates, I 'should do various prototypes testing different hypotheses.' (It is easier said than done!) Thus the dialogue established with prototypes is regulated through a hypothesis-testing approach, which restricts and focuses the inflow of responses and issues arising in the process. We end up back in the discussion of the size of the holes, and his preference for knitting techniques. I point out that the very idea of a crochet knitted liner seems unbearable, the holes are too tight, no wind can come through. He counters claiming that "the skin does not really breath. What we have to resolve is its sweating."

A brief review of the literature reveals that contrary to his claim the skin is involved in respiration, it breathes (Stücker et al., 2002). Nevertheless, he is right, the problem is sweating, transpiration, the cooling mechanism of the skin. Then again, the issue is how to dissipate sweat or better still, how to dissipate heat and cool the stump. So, I stick to my baskets and continue inquiring about ways to do a mould for semi-cylindrical strips. The closest thing I find is 
corrugated cardboard, which is too weak and I imagine that the silicone will stick to it. Hákon suggests spraying painting in order to harden and cure it. It works! I get a smooth and hard corrugated mould and a little later I am curing my first batches of semi-cylindrical strips.

Friðrik and I converse about my advances with the basket, about some of the experiments curing textile strips inside silicone and about my future intentions and difficulties fixing the liner to the basket. I will get a load of information just by having the amputees test how it feels when they wear it. 'You do not have to test everything simultaneously, and it does not have to be beautiful.' Indeed, after talking to him it is apparent that the real problem is how to keep the cohesion of the basket: how to weave it and keep it tight. Sticking it to the liner is another problem. Later, thinking how to preserve my prototypes, I start to think that cohesion is actually also an issue with flat reed baskets. Basket makers resolve it tying the strips with strings. Tying the strips of silicone works, at least through a test.

\section{Walking on baskets}

Baldur, one of the amputees from Team Össur, helps me informally testing a prototype. I hand him apprehensively a silicone basket hoping that the knots will hold, and the basket will not fall into pieces. He holds it carefully: 'It looks like something you want to be the first to try on, but you have to cut these so that I can fit it on', he says pointing out to some protruding unwoven strips that I failed to cut before (see Fig. 1). I give it a haircut so that it does not look like a jellyfish anymore. He examines it again, and tries it on. He agrees with Friðrik, the holes are too big. Moreover, it is oversized and short. 'You see, the sleeve should come 
up to here.' He points out, indicating just below his groin. He puts his liner over it and walks a few steps. He feels no pressure marks. Later on, I find on my desk a cast of his stump, which should enable me to get a better fit.

Figure 1 Prototypes of breathing liner

Producing the long sleeve of the liner would take forever. So trying to bypass the problem, I am, again, finding ways to glue the basket to a liner. The silicone glue does not hold, and in theory, silicone cannot be cured over silicone. Indeed, it does not hold. However, it gives me another idea curing silicone to hold a knotted strip. Surrounding the knot should be sufficient to maintain the structure of the basket in place. The experiment works. Not only does the knot structure hold in place, but also the silicone sticks to the thin edges of my strips smoothing and homogenizing them further. I try on one of my baskets and it works.

In the subsequent days, the task of weaving becomes easier, and I produce a number of prototypes. Nevertheless, my cardboard strip-mould deteriorates and I cannot find anymore cardboard. So, although better woven, my strips are bumpy. Moreover, modelling over Baldur's cast I have been testing ways to tense the silicone strips with weights, thereby weaving tighter.

I present Baldur with a series of prototypes. He looks at them with interest and then tries some of them on. However, this time he is rougher. He stretches them trying to pull them upwards. I am in anguish. 'It is too small and the holes are too big' he says showing me his skin bumping through the holes with a friendly annoyance, as he stretches the fabric further, straining it and his skin, along with my nerves. Moreover, the strips are spinning around and he is feeling pressure points. The test is a failure. The reason seems to be clear: the 
holes are too big. However, they were bigger the first time, which poses a dilemma. As I watch him try it on, I start thinking I could cure silicone over the whole basket and make holes putting tiny screws on the cast.

The following week Baldur and Símon try the silicone covered basket prototype on. Baldur thinks the one-millimetre holes are still too big, the holes still pull his skin through. However, he acknowledges that the size of the holes is easily adjustable. Taking this as a partial success, I fail to take into account that the tension, which has allowed me to weave tighter, might be what is squeezing Baldur's stump. Símon, on the other hand, likes it. He feels some pressure points, at particular points, which I mark and turn out to be thicker strips and bubbles not properly covered in silicone.

Early on the following week I present the collection of prototypes in a meeting of the group. Mímir seems satisfied. He considers the project concluded, it has produced plenty of results, which he claims will be of assistance in the design of a breathing liner. However, after a year the issue is still waiting to be resolved, perhaps Jónas is right you cannot hire nine mothers to deliver a baby in one month.

Testing a prototype defines whether a development is on the right track of or not. Test may assess diverse kinds developments under a variety of conditions. For example, a test may assess whether a potential material has desirable physical properties (i.e. whether it has adequate flexibility or durability), aesthetic properties (i.e. whether which textures are more pleasant to the tact), whether the device made of this material performs its function adequately (e.g. it holds together), or whether it produces the desired effects in the interaction with the body of the amputee (e.g. reduces sweatiness). The 
ultimate test for a new product, one which cannot be characterized as an iteration of a previous product, involves amputee test subjects in blinded experiments, aimed at convincing regulatory authorities that such a biomedical development is first: not noxious to the patient, and second that it contributes to improve a condition. Following strict double blind scientific as well as ethic, protocols, such tests are extremely costly. However, if the innovation can be considered as a modification of a previously licenced technology amputee test subjects often collaborate informally providing extremelly useful subjective feedback. Subjective testing of prototypes depends on the ability of researcher and the test subject to communicate with one another: What is it that the prototype trying to achieve? How does the prototype need to be built in order to be tested? What is the experience of the amputee? And, what are its implications for future developments? Communication depends on building a relation and satisfying the expectations generated by previous prototypes tested. And part of the problem is agreeing on how to test it. My ultimate aims were to test whether the basket liner addressed the issue of transpiration and whether its structure would cause pressure points. During the first test Baldur was enthusiastic and suggested it did not cause pressure points. However, the basket was too loose which might imply that pressure points might arise when the tightness is adjusted, it was also too low. I did not realize it then but his second observation referring to the length might be the pre-condition to being able to test the liner under conditions involving transpiration. Failing to meet this requirement, for his second test and perhaps the excessive tightness of the following prototype changed his attitude. The third test was equally failed with Baldur but successful 
with Simon, possibly revealing problems of developing the adequate size for the prototype.

\section{Discussion}

Drawing on the history of science and presupposing a distinction between social and biological realms, Mary Douglas, assumed that the relation between institutional and non-human formal structures was necessarily analogical. Analogies with nature discovered by scientists served as cognitive devices substantiating and communicating conventions reached between humans, thereby funding institutions. Exploring biosociality(Rabinow, 1999; Rabinow, 2009; Rabinow and Dan-Cohen, 2005; Gibbon and Novas, 2008; Ingold and Palsson, 2013; Palsson, 2009), new materialism (Tsing, 2015; Haraway, 2016; Haraway, 2008; Bennett, 2010) and actor network theory (Latour, 1999; Pythinen and Tamminen, 2011; Latour, 1988), several authors have demonstrated how human and non-human realms interact in far more nuanced ways, which diffuse such clear distinctions. This work with lower-limb prosthetic's R\&D hinges at how human and non-human structures are tightly interrelated in a bidirectional semantic flow, in which relations with the material world are build up mirroring social ideas and debates, while simultaneously understandings of the material world permeate onto how people relate to one another. The intricacy of biosocial relations implies that other tropes besides analogies may be more suitable to capture biosocial relations, and the institutions they structure.

The internship developed for this ethnography allowed us to witness some of the interactions between biosocial relations and institutional structures 
of corporate life at Össur. The ethnography focused on R\&D in the liner platform, which was identified as the fundament of the corporation. It is likely that a focus on the currently larger artificial knee platform, or in the cutting-edge neuronal interphases would have rendered different perspectives. The liner platform allows a stronger historical perspective, which suggests that the structures and dynamics of the corporation result from its developmental history, and are is intrinsically related with its products and the knowledges or understandings of the body these products crystallise. The ethnography also provided a privileged vantage point to observe the relations involved in the development of technology that seeks to emulate biological functions, in reciprocated interaction with the people and bodies, for which those functions are performed.

At first sight, the liner could be seen as a prosthetic accessory, a prosthetic of the prosthetic proper. Nevertheless, providing protection, shock absorption, structural support, and attachment to the residual limb it addresses fundamental functions that must be resolved by every lower limb prosthetics. Consequently, the liner became an indispensable part of lower limb prostheses in general, highlighting some of the functions and corresponding biosocial relations performed and enabled by the distal skin of limbs, and by membranes more widely.

Like the liner to the prosthesis, the skin hardly features as an organ, and yet it is perhaps the largest and one of the most complex, performing a vast array of functions. From an evolutionary point of view the dermis, the skin, can be considered as the primordial organ, which becomes differentiated in three layers. The epidermis which corresponds to the skin, is also the one from where the neuronal system develops, through both phylogeny and ontogeny. In a 
similar fashion, already Freud emphasized the importance of the skin as the locus of tact and contact in the early constitution of the self. Anzieu (2018) further develops the argument suggesting the skin-ego as a vast metaphor or rather as a fluctuation between a metaphor and a metonym (Anzieu, 2018: 6), veering on synecdoche. The skin-ego envelops and contains, protects, and exposes, defining and blurring the limits of the self and the other, while retaining traces of these interactions in the process, reinforcing its structure in stress areas. It is this capacity to simultaneously define and to blur difference that is performed by the liner, and which allows the prostheses to be incorporated, to be a continuous part of the body. In a similar fashion these characteristics make the skin a fundamental means of social interaction, and differentiation (Jablonski, 2013; Turner, 2012). Contemporary society may further hyperbolize these functions through representation and commodification (Borgerson and Schroeder, 2018). However, it is in the very mechanical and aesthetic functions where ambiguity and complexity lays, affording forms of sociality or biosociality that may be shared by membranes in organisms by borders for societies. Some of these biosocial relations, in particular the relation between contact and insulation, seem to be further emphasized in the Circumpolar environments (Sonne, 2007), where the skin seems to play an even more fundamental role defining the properties of being.

The current architectural distribution of Össur's headquarters is an actively intended design, which repurposes previously existing buildings, aiming to optimise certain forms of interaction amongst some workers, e.g. researchers in each of the platforms, and orthotist-prosthetists and costumer-patients. In agreement with what Mimir identifies as an Icelandic character, the corporate 
architecture employs various features flattening out hierarchies, and fostering primus inter-pares, (first amongst equals) interactions between co-workers.

In contrast to the case of the R\&D of heart prosthetics explored by Sharp (2013), the R\&D of Lower-limb prosthetics at Össur is highly exposed. This difference can be partially explained because lower-limb prosthetics are exposed, visible and palpable to patients who, to a large extent, can decide whether and how to use them, even contravening medical advice. Consequently, there are incentives to develop a high degree of interaction between patientcostumers or and prosthetists-orthotists. In line with this dynamic, Össur's R\&D, in particular the liner platform, is highly exposed in its architectural position, in corporate marketing, and in its very function, working as conjuncture for the interaction with customers.

$\mathrm{R} \& \mathrm{D}$ is also the place that hosts guests from partner and rival companies and apprentice interns. It is the locus of a dialogue between researchers, patients, and artefacts-in-the-making, through which the corporation attempts to project its niche in new directions. Ultimately, R\&D is to Össur what the liner to the prosthesis, hence we can conceive it as a corporate skin. This trope was never made explicit by members of the corporation.

The processes of apprenticeship, allows us to perceive how R\&D at Össur works as a corporate skin, and how biosocial relations, tropes and institutions interact in the corporation. Apprenticeship involves simultaneously a process of enskillment and a socialization into the institutions, the structures and dynamics that characterize this form of corporate life. Most interns in R\&D, have already undergone tertiary formal education. They are not yet practitioners, and are not expected to learn to recreate the productive processes of the corporation. In fact, 
company secrets remain guarded and out of reach for them. Rather, through peer tutelage interns are expected to learn by doing, adapting their independent background, and their understanding of technology, and of the body to locally available resources and ways of thinking, towards the resolution of the crafting issues that arise for their research team in conjunctural circumstances. They must adapt or learn ways to negotiate their work habits, and their understandings of the body, and of the technologies being developed with peermentors, but also with the materials and artefacts available, and according to circumstances with test subjects or patients.

Interns in $\mathrm{R} \& \mathrm{D}$ afford the corporations with means to overcome the predispositions that established researchers have built in the course of their negotiations with materials, prototypes, amputees and with one another. By reinventing processes that have already been standardized, interns make evident technical developments affording previously unavailable possibilities, thereby allowing R\&D to adapt to ever changing environments.

However, like prostheses to the body, interns and their prototypes may also elicit corporate reactions. Polite tolerance, antagonist reactions towards interns and the imposition of apparently menial tasks suggested have been often described in a wide variety of contexts of apprenticeship (Coy, 1989; Lave and Wenger, 1991). Such antagonism towards apprentices may seek to restrict access to the trade, defending self or corporate interests, much like the reactions of an immune system stimulated by a potentially dangerous foreign body. Such possibility cannot be ruled out, although it is not fully warranted either. Rather it would seem that such antagonism reflects a more fundamental dynamic of this corporate processes, including creative developments: through which the 
different life experiences and approaches to life become articulated in the corporation and crystalized in its products. Although, in my case the task imposed was indeed cumbersome, it also provided unrivalled opportunities to interact and become acquainted with a wide variety of persons, with dissimilar understandings of the body, with techniques, and materials, engaging in a prototype-mediated conversation on what the callous skin is and how it could be imitated. This conversation elucidates the political process that articulates the different approaches to life constituting the corporation.

The generation of the prototype is a point where the artefact has not yet been defined as an object. The interaction can be highly subjective, producing a prototype is cumbersome, like a rich but somewhat frustrating dialogue in which things do not come out as you expected them. Following a scientific approach, researchers seek to isolate and test specific properties of the materials, artefacts, and the residual limb, exposing different prototypes to specific conditions. However, their labour is more closely related to that of the bricoleur described by Lévi-Strauss, they are continuously repurposing materials and artefacts, altering functions and consequently negotiating the tropes and conventions associated with them. Furthermore, unlike the scientists described by Douglas, they are not satisfied with constructing abstract theoretical models of reality from the collection of those individual observations, instead they have to develop artefacts that perform the functions they are trying to emulate, even when strained under the multiple transactions to which they will be exposed in the everyday life of the amputee. In order for the tests to be conductive, researchers must develop rapport with amputees. They must develop communication channels and trust. They must become familiarized with amputees, aware of the 
biosocial relations involved, to understand their needs and requirements, and how they experience the prototypes.

\section{Conclusions}

Prostheses like the liner attempt to replace organs belonging to organic wholes. Thus, they constitute and embody working and social understandings of life. As the prosthetic industry is increasingly dominated by a corporate culture, this working understanding results from a political process articulating the different life experiences and approaches to life that constitute a biomedical corporation, such as Össur. In turn, corporations like Össur have been structured and developed following processes of organic growth, which depend on their history and on local biosocial affordances. The growth of a company is partially explained by the articulating power of its products. That is, their capacity to articulate different meanings and functions in specific contexts. Corporate growth is made possible or constrained by the harmonious fitness of their products in determinate biosocial niches.

Prosthetic technologies congeal the dialectic between diverse understandings of the biology of the body (often paired with understandings of the workings of society), practices which may or not be aligned with those understandings, and the agencies of materials, bodies and of the corporation. Thereby developing these products fosters specific modes of socialization.

The body, is not only as a repository of cognitive devices anchoring the conventions that institutions are. The biological properties, the requirements and capacities of the body, the way to understand and emulate them are the very fields these conventions are negotiating, and by which they are structured, 
suggesting a strong sense of biosociality, acknowledging that human sociality is embedded and affects biological relations, while simultaneously being influenced by them.

There is no single organic trope, rather there is a plethora of changing tropes, which reveal their potential complexity when we examine the actual relations between organs and tools, between bodies and environments or the coconstitutive relations between human biology, technology and communities of practice.

\author{
Notes \\ 1. http://www.ossur.com/corporate/products (accessed 13/05/14) \\ 2. All the names have been replaced by pseudonyms. Different pseudonyms are sometimes given \\ to the same persons in different dialogues in order to avoid characterization and to maintain \\ their anonymity. \\ 3. http://www.ossur.com/corporate/inventors (accessed 13/05/14) \\ 4. https://www.youtube.com/watch?v=MVILvNRXxIs (accessed 14/08/2015)
}

\title{
Bibliography
}

Anzieu D. (2018) The Skin-Ego: A New Translation by Naomi Segal: Routledge.

Bennett J. (2010) Vibrant Matter: A Political Ecology of Things: Durham, Duke University Press.

Borgerson JL and Schroeder JE. (2018) Making Skin Visible:How Consumer Culture Imagery Commodifies Identity. Body \& Society 24: 103-136.

Burke K. (1969) A grammar of motives: Univ of California Press.

Cohen E. (2012) From Phantoms to Prostheses. Disability Studies Quarterly 32.

Coy MW. (1989) Apprenticeship: From Theory to Method and Back Again. New York: State University of New York Press. 
Cresswell T. (2009) The prosthetic citizen: New geographies of citizenship. Political power and social theory 20: 259-273.

Dimond R, Bartlett A and Lewis J. (2015) What binds biosociality? The collective effervescence of the parent-led conference. Social Science \& Medicine 126: 1-8.

Douglas M. (1986) How institutions think: Syracuse University Press.

Douglas M. (2002) Natural symbols, London: Routledge.

French L. (1994) The political economy of injury and compassion: amputees on the Thai-Cambodia border. In: Csordas TJ (ed) Embodiment and Experience: The Existential Ground of Culture and Self. Cambridge: Cambridge University, 69-99.

Gibbon S and Novas C. (2008) Biosocialities, Genetics and the Social Sciences: Making Biologies and Identities: Routledge.

Gieser T. (2008) Embodiment, emotion and empathy: A phenomenological approach to apprenticeship learning. Anthropological Theory 8: 299-319.

Haraway DJ. (1985) A manifesto for cyborgs: Science, technology, and socialist feminism in the 1980s: Center for Social Research and Education.

Haraway DJ. (2008) When Species Meet, Minneapolis: University Of Minnesota Press.

Haraway DJ. (2016) Staying with the Trouble: Making Kin in the Chthulucene: Duke University Press.

Ingold T and Palsson G. (2013) Biosocial Becomings: Integrating Social and Biological Anthropology, Cambridge: Cambridge University Press.

Jablonski NG. (2013) Skin: A natural history: Univ of California Press.

Jain SS. (1999) The Prosthetic Imagination: Enabling and Disabling the Prosthesis Trope. Science, Technology, \& Human Values 24: 31-54.

Kristinsson Ö. (1993) The ICEROSS concept: a discussion of a philosophy. Prosthetics and Orthotics International 17: 49-55.

Kurzman SL. (2001) Presence and Prosthesis: A Response to Nelson and Wright. Cultural Anthropology 16: 374-387.

Landecker H. (2009) Culturing Life: How Cells Became Technologies, Cambridge, MA: Harvard University Press.

Landecker H. (2016) Antibiotic Resistance and the Biology of History. Body \& Society 22: 19-52. 
Latour B. (1988) The Pasteurization of France followed by irreductions, Cambridge M.A.: Harvard University Press.

Latour B. (1999) Pandora's Hope: Essays on the Reality of Science Studies, Cambridge, MA: Harvard University Press.

Lave J and Wenger E. (1991) Situated learning: Legitimate peripheral participation: Cambridge University Press.

Lock M and Nguyen V-K. (2010) An anthropology of biomedicine. New York: John Wiley \& Sons.

Llinás R. (2001) I of the Vortex: From Neurons to Self, Cambridge, MA: MIT Press.

Marchand THJ. (2010) Making knowledge: explorations of the indissoluble relation between minds, bodies, and environment. Journal of the Royal Anthropological Institute 16: S1-S21.

Martin A. (2010) Microchimerism in the Mother (land): Blurring the Borders of Body and Nation. Body \& Society 16: 23-50.

Mauss M. (1934) Body Techniques Sociology and Psycology: Essays. London: Routledge \& Keegan Paul (1979 Trad.), 97-123.

Milosavljevic KL. (2013) Life and limb: prosthetic citizenship in Serbia. Social Anthropology. University of Edinburgh.

Nabila A. (2013) Exploring Craftsmanship: Bamboo Weaving. Available at: https://www.youtube.com/watch?v=MVlLvNRXxIs.

Nelson DM. (2001) Stumped Identities: Body Image, Bodies Politic, and the Mujer Maya as Prosthetic. Cultural Anthropology 16: 314-353.

Össur Corporate. (2014a) Inventors. Available at: http://www.ossur.com/corporate/about-ossur/companybackground/inventors.

Össur Corporate. (2014b) Products. Available at: http://www.ossur.com/corporate/products.

Palsson G. (2009) Biosocial Relations of Production. Comparative Studies in Society and History 51: 288-313.

Pythinen $\mathrm{O}$ and Tamminen S. (2011) We have never been only human: Foucault and Latour on the question of the anthropos. Anthropological Theory 11: 135-152.

Rabinow P. (1999) From sociobiology to biosociality. The science studies reader: 407. 
Rabinow P. (2009) Anthropos today: Reflections on modern equipment: Princeton University Press.

Rabinow P and Dan-Cohen T. (2005) A machine to make a future: Biotech chronicles: Princeton University Press.

Radcliffe-Brown AR. (1940) On social structure. The Journal of the Royal Anthropological Institute of Great Britain and Ireland 70: 1-12.

Ricoeur P. (1980 [1975]) La metáfora viva, Madrid: Ediciones Europa.

Scheper-Hughes N and Lock MM. (1987) The Mindful Body: A Prolegomenon to Future Work in Medical Anthropology. Medical Anthropology Quarterly 1: 6-41.

Sharp LA. (2013) The Transplant Imaginary: Mechanical Hearts, Animal Parts, and Moral Thinking in Highly Experimental Science, Berkeley, CA, USA: University of California Press.

Shorey P. (1969) Republic. Plato in Twelve Volumes, Vols. 5 \& 6 translated by Paul Shorey. Cambride, MA; London: Harvard University Press; William Heinemann, Perseus Digital Library Project. Ed. Gregory R. Crane. Tufts University.

Simpson E. (2006) Apprenticeship in Western India. The Journal of the Royal Anthropological Institute 12: 151.

Sobchack V. (2006) A leg to stand on: Prosthetics, metaphor, and materiality. In: Smith M and Morra J (eds) The prosthetic impulse: From a posthuman present to a biocultural future. Cambridge, MA: MIT Press, 17-41.

Sonne B. (2007) La vie est un sac rempli d'air Polysémie de Pooq et autres notions associées. Anthropologie et Socíétés 31: 15-36.

Steve H, John A, Stephanie L, et al. (2013) Biosecurity and the topologies of infected life: from borderlines to borderlands. Transactions of the Institute of British Geographers 38: 531-543.

Stücker M, Struk A, Altmeyer P, et al. (2002) The cutaneous uptake of atmospheric oxygen contributes significantly to the oxygen supply of human dermis and epidermis. The Journal of Physiology 538: 985-994.

Tsing AL. (2015) The mushroom at the end of the world: on the possibility of life in capitalist ruins: Princeton University Press.

Turner TS. (2012) The social skin. HAU: Journal of Ethnographic Theory 2: 486504.

Wright MW. (2001) Desire and the Prosthetics of Supervision: A Case of Maquiladora Flexibility. Cultural Anthropology 16: 354-373. 